\title{
Mycoplasma Pneumonia: Late Treatment Leading to Acute Respiratory Distress Syndrome and Renal Failure
}

\author{
A. Graham Cummiskey ${ }^{1}$, Michael Reardon ${ }^{2}$ \\ ${ }^{1}$ Connolly Hospital, Blanchardstown, Dublin, Ireland \\ ${ }^{2}$ Wexford General Hospital, Wexford, Ireland
}

Received: 27/11/2018

Accepted: 09/01/2019

Published: $13 / 02 / 2019$

\begin{abstract}
How to cite this article: Cummiskey AG, Reardon M. Mycoplasma pneumonia: late treatment leading to acute respiratory distress syndrome and renal
\end{abstract} failure. EJCRIM 2019;6: doi:10.12890/2019_001003.

Conflicts of Interests: The Authors declare that there are no competing interests.

This article is licensed under a Commons Attribution Non-Commercial 4.0 License

\section{ABSTRACT}

Introduction: Mycoplasma pneumonia is one of the most common types of pneumonia, although it is often not diagnosed due to mild clinical course.

Aims: In this case study we aim to describe the importance of considering mycoplasma pneumonia in high-risk groups.

Methods: We present the case of a 27-year-old woman admitted with pneumonia, progressing to acute respiratory distress syndrome and acute kidney injury. She had a prolonged stay in the ICU, requiring intubation and continuous veno-venous haemofiltration (CVVH). After 1 month in hospital, she was discharged with full recovery.

Discussion: Mycoplasma pneumonia is a common type of pneumonia in the community, but only a small percentage of patients require hospitalization. Delayed treatment can result in multi-organ failure, which requires intensive care and long hospital stays.

\section{LEARNING POINTS}

- Delayed initiation of proper treatment allowed our patient's mycoplasma pneumonia to progress to acute respiratory distress syndrome and acute kidney injury.

- The British Thoracic Society does not recommend blanket empiric treatment of mycoplasma pneumonia, although other European and American guidelines do, and so it is important to consider this organism in high-risk groups to prevent severe complications.

\section{KEYWORDS}

Mycoplasma pneumonia, acute respiratory distress syndrome

\section{INTRODUCTION}

Mycoplasma pneumonia (MP) is the most common type of atypical community-acquired pneumonia (CAP). It typically occurs in young adults, in epidemics every 4-5 years [1]. Symptoms include headache, malaise, low-grade pyrexia and an unproductive cough. Our case demonstrates a rare example of acute respiratory distress syndrome (ARDS) and acute kidney injury (AKI) secondary to delayed treatment of MP.

\section{CASE PRESENTATION}

A 27-year-old intellectually disabled woman presented to our hospital with a 3-day history of productive cough, abdominal pain, diarrhoea and pyrexia. She had no history of recent illness, travel or exposure to ill persons. She lived at home with her parents, and attended a workshop 3 days a week. On review, she was alert, with a temperature of $37.6^{\circ} \mathrm{C}$, respiratory rate $22,95 \%$ oxygen saturation on room air, blood pressure $108 / 94 \mathrm{mmHg}$ and heart rate $127 \mathrm{bpm}$. She had bibasal crepitations on respiratory auscultation but examination was otherwise normal. Her 
chest x-ray demonstrated bilateral consolidations (Fig. 1) and her laboratory results were: CRP 254.1, WCC 9.2, neutrophils 7.72, Hb 15.3, creatinine 70, Na 134, K 3.5. Her CURB65 score was 1. She was admitted with suspected CAP and given intravenous co-amoxiclav.

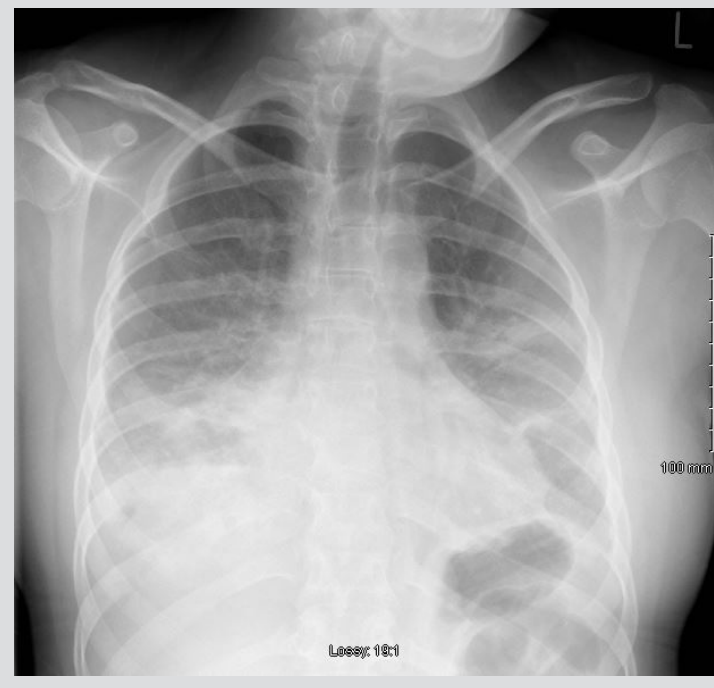

Figure 1. Admission chest $x$-ray showing bilateral consolidation

\section{METHODS AND PROCEDURES}

The patient acutely deteriorated on day 5 , with oxygen saturations of $62 \%$ on room air. Her arterial blood gases showed a pH of 7.5 , $\mathrm{PCO}_{2}$ 4.86, $\mathrm{PO}_{2} 4.0$ and lactate 2.31. Her respiratory rate was 38, heart rate 152, and blood pressure 105/68 mmHg. She was transferred to the intensive care unit (ICU) for intubation due to lack of compliance on oxygen. A repeat chest $x$-ray demonstrated bilateral mid and lower lobe consolidation and parapneumonic effusions with the development of acute respiratory distress syndrome (ARDS) (Fig. 2). Clarithromycin was started for suspected mycoplasma infection on day 5 , which was changed to doxycycline on day 10 , after a positive mycoplasma IGM result.

During her stay in the ICU, the patient developed acute renal failure, requiring two episodes of continuous veno-venous haemofiltration $(\mathrm{CVVH})$, and a Coomb-positive haemolytic anaemia resulting in red blood cell transfusions. She improved clinically on day 20 , with cessation of the CVVH, and was extubated on day 23, after being intubated for 18 days. She was transferred from the ICU to the ward on nasal highflow oxygen at $50 \%$, no longer requiring oxygenation by day 26 . She completed a 14 -day course of doxycycline. She was discharged after 1 month, and was much improved in clinic after 2 months, with follow-up chest x-ray showing interim improvement with bilateral ground-glass opacification (Fig. 3).

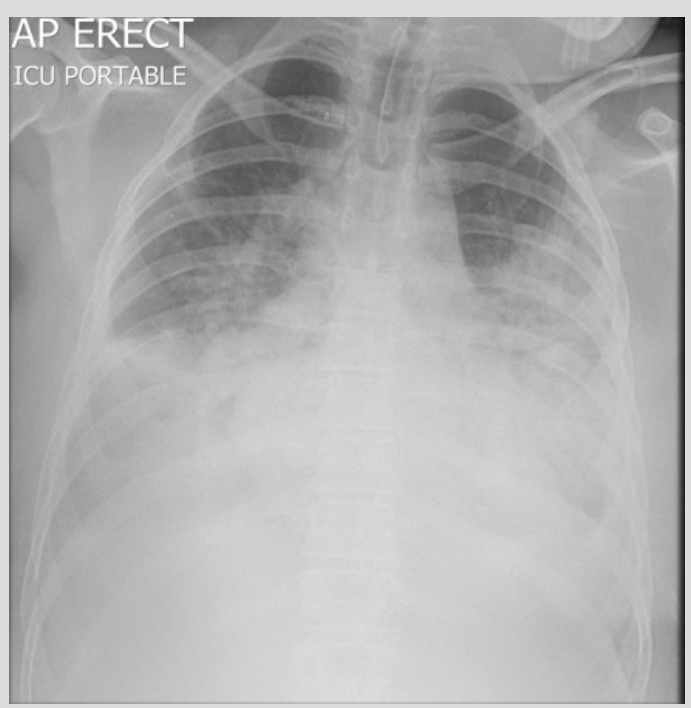

Figure 2. Chest $x$-ray in the ICU demonstrating the development of acute respiratory distress syndrome

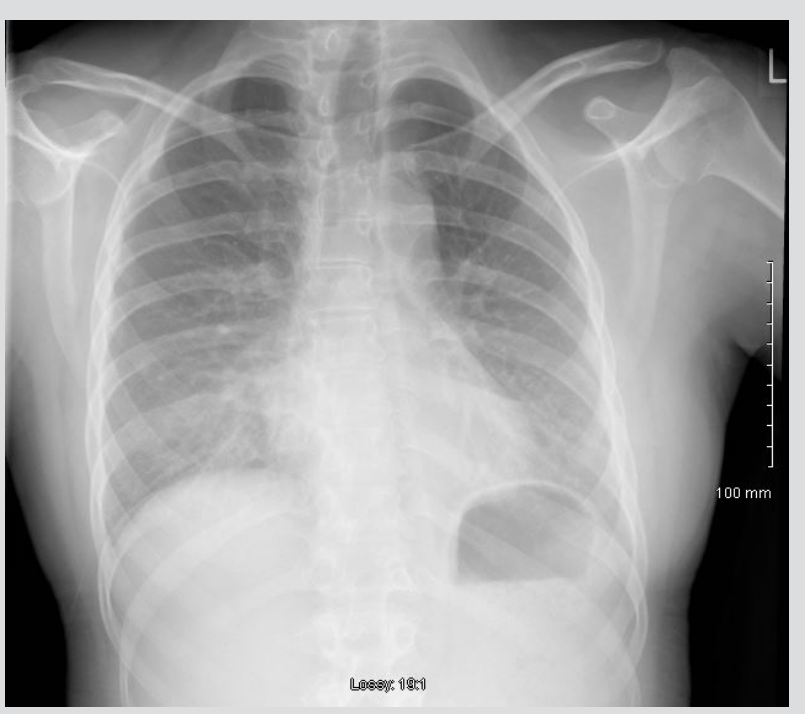

Figure 3. Follow-up chest $x$-ray showing interim improvement with bilateral ground-glass opacification 


\section{DISCUSSION}

Mycoplasma pneumonia is a common type of CAP, contributing to around $10-30 \%$ of cases $^{[2]}$. The clinical course is usually mild, although around $10.9 \%$ of patients admitted with MP required mechanical ventilation and $3-4 \%$ developed ARDS ${ }^{[2]}$. British Thoracic Society guidelines for CAP do not recommend empiric cover for atypical organisms, since covering empirically for MP in all cases was considered inappropriate ${ }^{[1]}$. The European Respiratory Society recommends using oral amoxicillin plus clarithromycin to cover for atypical organisms in patients with CURB65 scores greater than or equal to $2^{[4]}$. The European CAP Guidelines recommend that inpatients are treated with amoxicillin plus a macrolide ${ }^{[5]}$, as do The Infectious Diseases Society of America/American Thoracic Society Consensus Guidelines ${ }^{[6]}$.

\section{CONCLUSION}

Our patient was admitted with bilateral pneumonia of unknown pathogenicity, and quickly deteriorated on broad spectrum antibiotics, requiring intubation and ICU treatment. Due to delayed initiation of proper treatment, her infection progressed to include AKI and haemolytic anaemia. Adoption of a more comprehensive clinical approach to antimicrobial therapy as suggested by European CAP guidelines in patients at high risk of atypical pneumonia may result in better clinical outcomes for such patients.

\section{REFERENCES}

1. Lim WS, Baudouin S, Geroge RC, Hill AT, Jamieson C, Le Jeune I, et al. Guidelines for the management of community acquired pneumonia in adults. British Thoracic Society Reports 2009, 1(3).

2. Miyashita N, Obase Y, Ouchi K, Kawasaki K, Kobashi Y, Oka M. Clinical features of severe Mycoplasma pneumoniae pneumonia in adults admitted to an intensive care unit. J Med Microbiol 2007;56:1625-1629.

4. Cilloniz C, Schultz M, van der Eerden M. Community-acquired pneumonia. European Respiratory Society, 2017. Available from: hhttps://erj.ersjournals.com/ content/50/3/1700582.long

5. Lode HM. Managing community-acquired pneumonia: a European perspective. Respir Med 2007;101:1864-1873.

6. Mandell LA, Wunderink RG, Anzueto A, et al. Infectious Diseases Society of America/American Thoracic Society consensus guidelines on the management of communityacquired pneumonia in adults. Clin Infect Dis 2007;44(Suppl 2):S27-S72. 